PREPARED FOR THE U.S. DEPARTMENT OF ENERGY, UNDER CONTRACT DE-AC02-76CH03073

PPPL-3641

PPPL-3641

UC-70

Confinement of Neutral Beam lons in the

National Spherical Torus Experiment

by

D.S. Darrow, S.S. Medley, A.L. Roquemore, and A. Rosenberg

December 2001

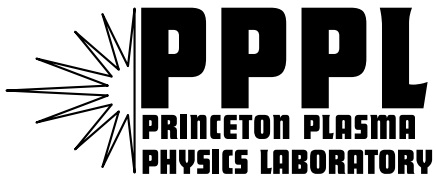

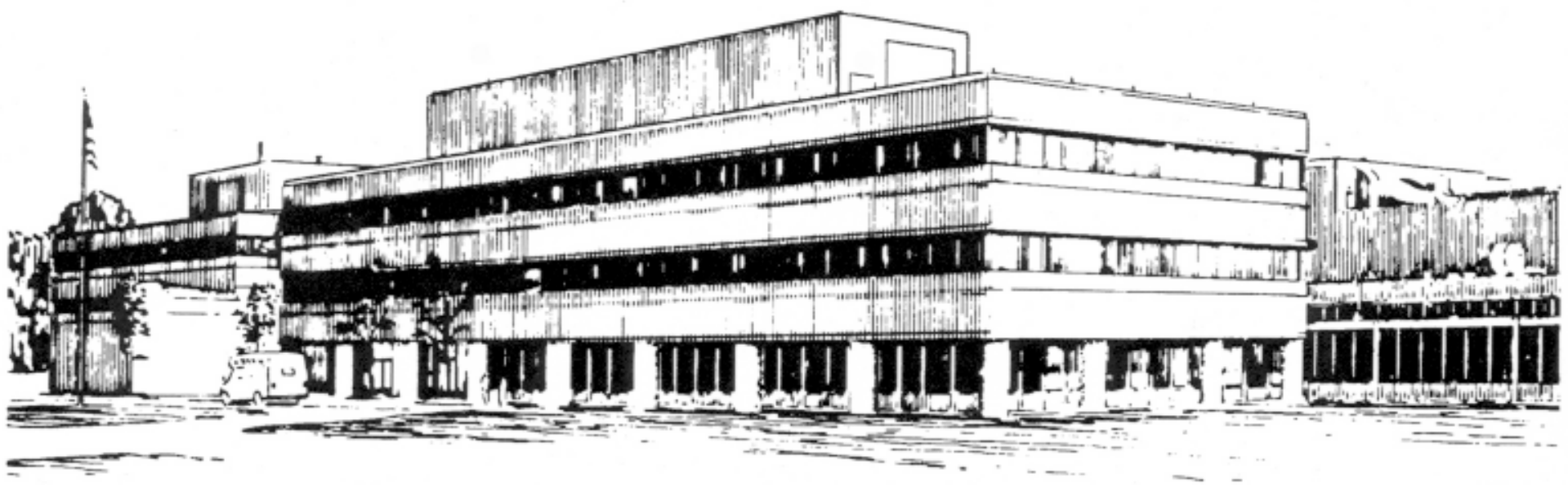

PRINCETON PLASMA PHYSICS LABORATORY PRINCETON UNIVERSITY, PRINCETON, NEW JERSEY 


\section{PPPL Reports Disclaimer}

This report was prepared as an account of work sponsored by an agency of the United States Government. Neither the United States Government nor any agency thereof, nor any of their employees, makes any warranty, express or implied, or assumes any legal liability or responsibility for the accuracy, completeness, or usefulness of any information, apparatus, product, or process disclosed, or represents that its use would not infringe privately owned rights. Reference herein to any specific commercial product, process, or service by trade name, trademark, manufacturer, or otherwise, does not necessarily constitute or imply its endorsement, recommendation, or favoring by the United States Government or any agency thereof. The views and opinions of authors expressed herein do not necessarily state or reflect those of the United States Government or any agency thereof.

\section{Availability}

This report is posted on the U.S. Department of Energy's Princeton Plasma Physics Laboratory Publications and Reports web site in Fiscal Year 2002. The home page for PPPL Reports and Publications is: http://www.pppl.gov/pub_report/

DOE and DOE Contractors can obtain copies of this report from:

U.S. Department of Energy

Office of Scientific and Technical Information

DOE Technical Information Services (DTIS)

P.O. Box 62

Oak Ridge, TN 37831

Telephone: (865) 576-8401

Fax: (865) 576-5728

Email: reports@adonis.osti.gov

This report is available to the general public from:

National Technical Information Service

U.S. Department of Commerce

5285 Port Royal Road

Springfield, VA 22161

Telephone: 1-800-553-6847 or

(703) 605-6000

Fax: (703) 321-8547

Internet: http://www.ntis.gov/ordering.htm 


\title{
Confinement of Neutral Beam Ions in the National Spherical Torus Experiment
}

\author{
D. S. Darrow, S. S. Medley, A. L. Roquemore, and A. Rosenberg \\ Princeton Plasma Physics Laboratory, PO Box 451, Princeton, New Jersey 08543, USA
}

\begin{abstract}
The loss of neutral beam ions to the wall has been measured in the National Spherical Torus Experiment (NSTX) by means of thermocouples, an infrared (IR) camera, and a Faraday cup probe. The losses tend to exhibit the expected dependences on plasma current, tangency radius of the injector, and plasma outer gap. However, the thermocouples and the Faraday cups indicate substantially different levels of loss and this difference has yet to be understood.
\end{abstract}

\section{Introduction}

Spherical tokamaks (STs) have been found, both theoretically ${ }^{1}$ and experimentally ${ }^{2}$, to be capable of confining plasmas at high beta, a quality attractive for prospective fusion reactor applications. NSTX ${ }^{3}$ is an ST with typical parameters of $\mathrm{R}=0.86 \mathrm{~m}, \mathrm{a}=0.68 \mathrm{~m}, \mathrm{\kappa}=2, \mathrm{~B}_{\mathrm{T}}=0.3$ $\mathrm{T}, \mathrm{I}_{\mathrm{p}}=1 \mathrm{MA}, \mathrm{n}_{\mathrm{e} 0}=3 \times 10^{19} \mathrm{~m}^{-3}$, and $\mathrm{T}_{\mathrm{e} 0}=1 \mathrm{keV}$. To reach fusion temperatures and high beta, auxiliary heating is needed, the simplest form being neutral beam (NB) heating. NB heating has been applied to NSTX, commencing in September 2000, and has resulted in toroidal beta values of up to $\sim 25 \%$. On NSTX, deuterium ions are injected at $80 \mathrm{keV}$ from three sources, yielding a maximum possible injection power of $5 \mathrm{MW}$. The sources have tangency radii of $0.487,0.592$, and $0.694 \mathrm{~m}$.

Because efficient NB heating depends upon good confinement of the injected ions, we have undertaken measurements of the loss rate of NB ions. In addition to assessing the quality of confinement, this study should also reveal if there are any conditions of extreme losses in which the limiters or walls might be damaged. Loss measurements also reveal details of the physics of events that cause loss and aid in benchmarking numerical models of loss processes. Finally, understanding the loss of NB ions in NSTX provides a good framework for prediction of alpha particle losses in at deuterium-tritium fueled ST in that the dimensionless parameters $\left(\rho / \mathrm{a}\right.$ and $\left.\beta_{\text {fast }}\right)$ are similar between the two systems.

\section{Prompt Orbit Loss Modeling}

The most fundamental and irreducible loss of fast ions arises from prompt orbit loss, meaning that beam ions are born onto orbits that intersect the limiters or vessel wall. This loss process has been modeled by the EIGOL code ${ }^{4}$, which follows the full gyroorbits of NB ions using EFIT-generated magnetic equilibria, a detailed description of the internal structures in the vacuum vessel, and an accurate model of the beam deposition profile. It is important to retain the full gyromotion of the beam ions because their typical gyroradius is $0.2 \mathrm{~m}$, which is non-negligible compared to the plasma minor radius of $\sim 0.7 \mathrm{mEIGOL}$ simulations show that $\mathrm{I}_{\mathrm{p}}, \mathrm{q}_{0}$, and $\delta_{\text {outer }}$ (the distance between the separatrix and the limiter) have the strongest effect on the loss rate. Other parameters, such at $\mathrm{B}_{\mathrm{T}}$ and $\mathrm{n}_{\mathrm{e} 0}$, have considerably less influence. Figure 1 depicts the computed global loss fraction for a number of different cases with varying $\mathrm{I}_{\mathrm{p}}, \mathrm{q}_{0}$, and $\delta_{\text {outer }}$. The loss fraction rises as the plasma current is reduced, going from $\sim 15 \%$ at $\mathrm{I}_{\mathrm{p}}=1 \mathrm{MA}$ to $\sim 85 \%$ at $0.25 \mathrm{MA}$. However, if the outer gap is increased from $3.7 \mathrm{~cm}$ to $14.4 \mathrm{~cm}$, the loss fraction at $1 \mathrm{MA}$ drops to $\sim 2 \%$. Conversely, if $\mathrm{q}_{0}$ 


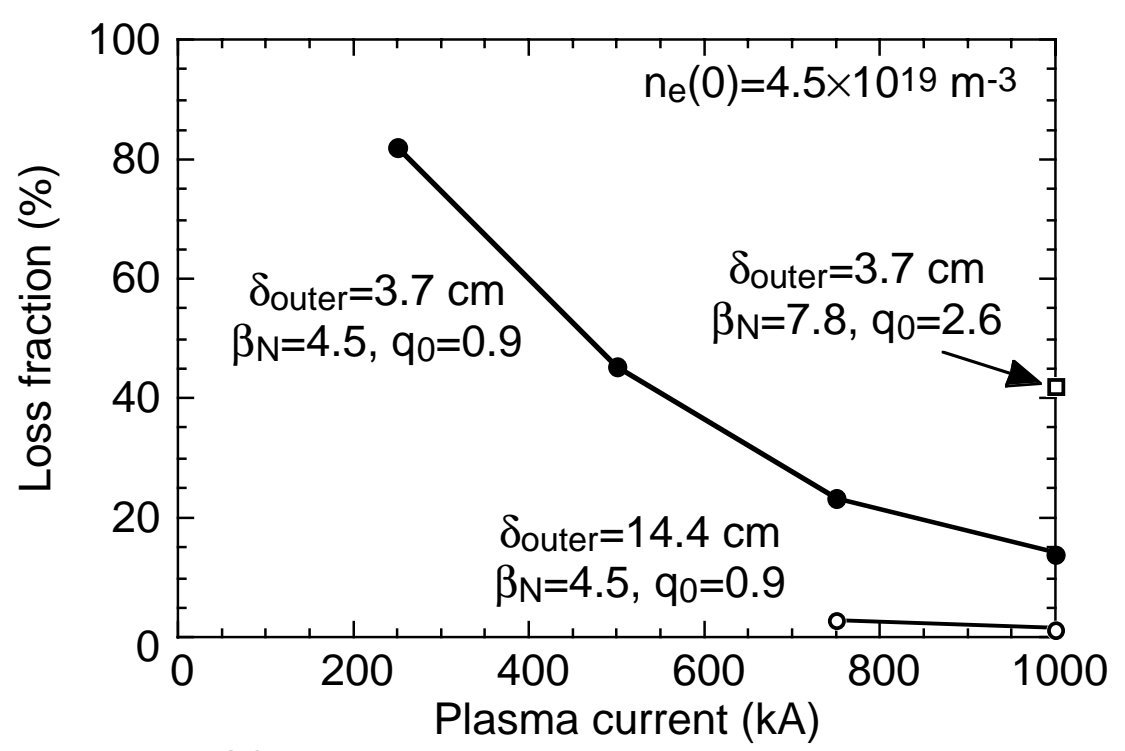

Figure 1 EIGOL computed loss fraction as a function of plasma current, outer gap, and $\mathrm{q}_{0}$.
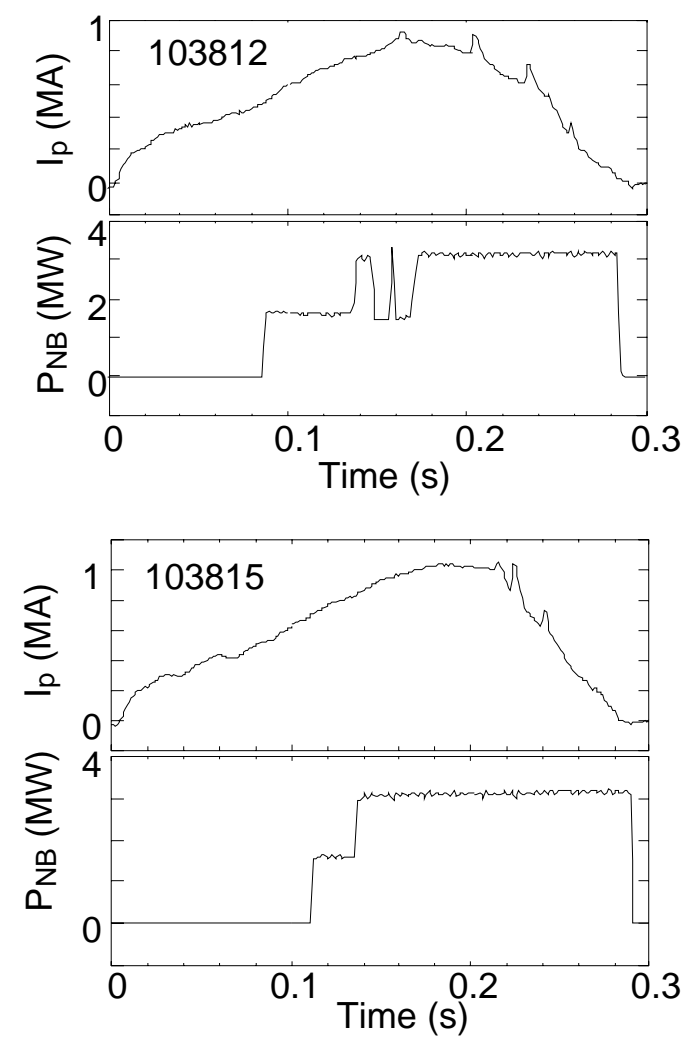

Figure 2 Plasma current and NB power waveforms for two shots with thermocouple data. For shot 103812, a temperature rise of $17^{\circ} \mathrm{C}$ was observed in the antenna protective plates and for shot 103815 , a rise of $3.5^{\circ} \mathrm{C}$ was seen. is raised from 0.9 to 2.6 at $\mathrm{I}_{\mathrm{p}}=1 \mathrm{MA}$, the global loss fraction rises from $\sim 15 \%$ to $42 \%$. The loss fraction varies only a few percent at constant $I_{p}$ as $n_{e}(0)$ changes.

\section{Beam Ion Loss Diagnostics}

On NSTX, there are several diagnostics that can provide information concerning NB ion loss rates. The first two of these diagnostics are associated with the high harmonic fast wave (HHFW) antenna. The antenna is the largest object in the vicinity of the

midplane; it projects inward from the vessel wall by $10 \mathrm{~cm}$, to $\mathrm{R}=1.58 \mathrm{~m}$ at the midplane, and it subtends $90^{\circ}$ toroidally. Because the orbits of beam ions reach their farthest from the magnetic axis in the vicinity of the outboard midplane, the antenna is the place where many beam ions are lost. On the side of the antenna where beam ions strike there are boron nitride protective plates, $1 \mathrm{~cm}$ thick. By measuring the temperature rise of the protective plates during a shot, either with thermocouples or an IR camera, the total integrated flux of beam ions to the plate can be inferred. The thermocouple temperatures are digitized once every few seconds, and hence are useful only to measure the integrated energy absorbed by the protective plates. The IR camera can, in principle, give time-resolved surface temperature measurements, but requires calibration for the emissivity of the protective plate surface.

Beam ion loss at the vessel midplane is also measured by a Fast Lost Ion Probe (FLIP), which utilizes Faraday cups ${ }^{5}$. The probe has three apertures, at $\mathrm{R}=1.607,1.632$, and $1.661 \mathrm{~m}$. These Faraday cups are located behind apertures that prohibit $\mathrm{D}$ ions with energies below $1 \mathrm{keV}$ from reaching the cups. In addition, a cylinder internal to the probe is biased to $-50 \mathrm{~V}$ to suppress secondary electrons that may result from beam ion impact on the Faraday cups. Signals from this diagnostic are typically digitized at $10 \mathrm{kHz}$ and are absolutely calibrated. 


\section{Beam Ion Loss Measurements}

The protective plate thermocouples show no discernable temperature rise during ohmic shots, but do register a temperature increase during NB injection. EIGOL simulations predict a protective plate temperature rise of $8^{\circ} \mathrm{C} /(\mathrm{MW}-\mathrm{s})$. Shown in Fig. 2 is shot 103815 with $\mathrm{I}_{\mathrm{p}}=1$ MA, had $3 \mathrm{MW}$ NBI for $0.17 \mathrm{~s}$, including some injection during the plasma current rampdown. If the current had been held at $1 \mathrm{MA}$ throughout the injection period, the EIGOL result would predict a temperature rise of $4^{\circ} \mathrm{C}$ in the protective plates, suggesting that the actual temperature rise should have been $>4^{\circ} \mathrm{C}$. The observed rise was $3.5^{\circ} \mathrm{C}$, less than would be expected. However, a shot also shown in Fig. 2, 103812, with 3 MW injection for $0.2 \mathrm{~s}$ gives a temperature rise of $17^{\circ} \mathrm{C}$, about five times the temperature change for a very similar discharge. This temperature rise is probably in excess of what EIGOL would predict for this plasma current waveform, and may be the result of MHD activity and internal reconnection events (IREs) during NBI.

IR camera images have been digitized during NBI. Since the surface emissivity calibration

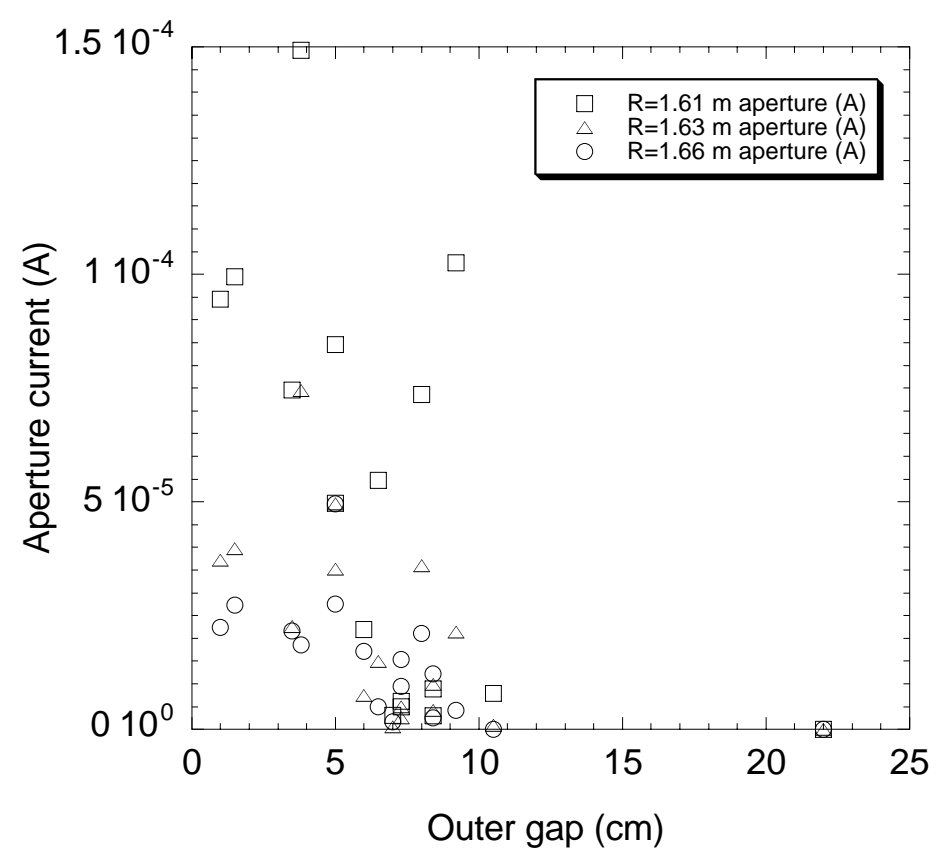

Figure 3 Beam ion loss as a function of outer gap distance for 0.7 MA, 0.3 T plasmas. for the protective plates has not yet been done, absolute temperatures and temperature rises cannot be reported. However, the scrape off profile of the NB ions on the side of the HHFW antenna has been recorded for a number of shots. Preliminary analysis shows a scrape off length of $\sim 2 \mathrm{~cm}$, somewhat shorter than the $4.2 \mathrm{~cm}$ predicted by EIGOL.

NB ion loss measurements have been made with the Faraday cup diagnostic for nearly every NBI plasma to date in NSTX. Figures 3 $\& 4$ display this data. These figures show the typical measured loss levels, which vary from a few $\mu \mathrm{A}$ to $\sim 200 \mu \mathrm{A}$. EIGOL calculations for a $1 \mathrm{MA}, 0.3 \mathrm{~T}$ plasma predict a beam ion flux of $10 \mathrm{MW} / \mathrm{m}^{3}$, which corresponds to a current of $1 \mathrm{~mA}$ in each aperture. So, the loss currents measured are in many cases much

smaller than expected. This is in contrast to the thermocouple data, which indicates losses of the same order or slightly less than EIGOL predicts.

Figure 3 shows the most obvious correlation of the loss rate found so far-the correlation with the outer gap spacing. This data is taken from discharges in which single neutral beam sources were injected for $3 \mathrm{~ms}$ long "blips" (shots 105692-105749). Even after screening this data set to eliminate cases with obvious MHD activity, there is still significant scatter in the data. A more careful screening of the data for MHD is planned.

Figure 4 displays the variation of the loss as a function of plasma current. Shown are the losses measured in the apertures at $\mathrm{R}=1.61$ and $1.63 \mathrm{~m}$. The losses in both apertures exhibit the trend of increasing loss as $\mathrm{I}_{\mathrm{p}}$ decreases. Figure 4 includes a plot of power law curve fits to the data that did not appear to have enhanced loss from MHD activity (solid curves). The fitted exponents are -2.82 and -4.04 respectively for the 1.61 and $1.63 \mathrm{~m}$ aperture data. On 
the same axes are plotted a power law fit to the EIGOL global loss calculation. The fits to the global loss are then scaled to coincide with the measured loss in each aperture at $1 \mathrm{MA}$. It is

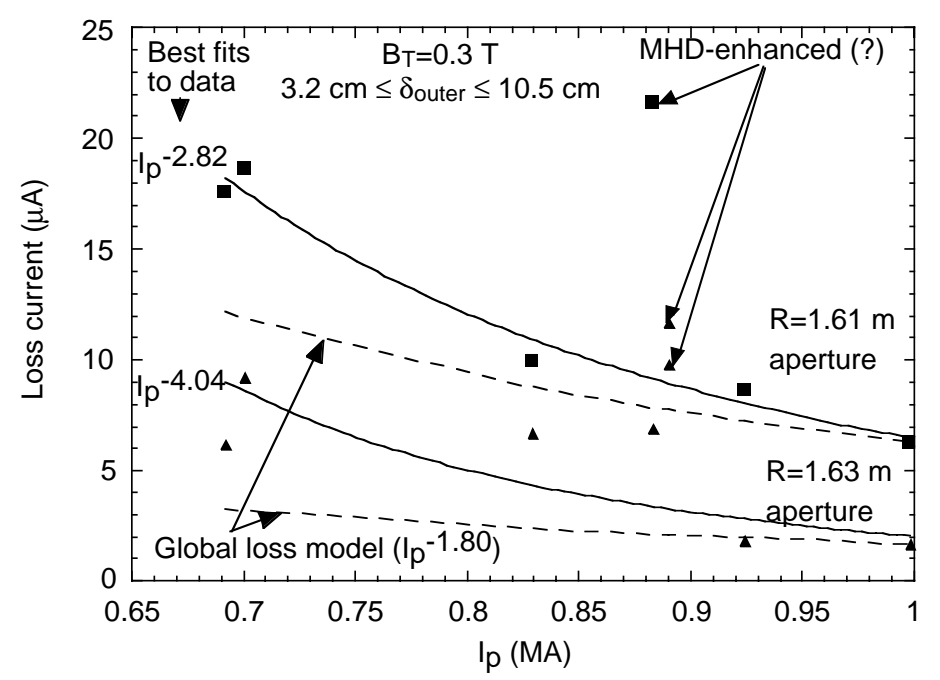

necessary to scale the fits because, as described above, the Faraday cup currents observed are significantly smaller than predicted by the model. This fit has an exponent of -1.90 , meaning that the model loss varies less rapidly with current than does the observed loss. This set of data includes plasmas with outer gap positions varying between 3.2 and $10.5 \mathrm{~cm}$. Given the strong dependence of the loss fraction on the outer gap distance, as seen in Fig. 3, this plot may not reflect the true variation of the loss with $I_{p}$.

Figure 4 Loss as a function of $\mathrm{I}_{\mathrm{p}}$ for two apertures. $\delta_{\text {outer }}$ varies between 3.2 and $10.5 \mathrm{~cm}$ for the shots shown.

\section{Summary}

Neutral beam ion losses in NSTX have been measured with thermocouples, an IR camera, and Faraday cups. Thermocouple data shows a loss rate at or somewhat below that predicted by the EIGOL code. Faraday cup measurements of the loss are substantially lower than predicted by the code. The loss rate varies strongly with the outer gap distance, and also with the plasma current.

\section{Acknowledgements}

This work was performed under US DoE contract number DE-AC02-76CH03073.

\section{References}

1. Y-K.M. Peng, Phys Plasmas 7 (2000) 1681.

2. S. M. Kaye, et al., Phys Plasmas 8 (2001) 1977.

3. J. Spitzer, M. Ono, M. Peng, et al., Fusion Technology 30, 1337 (1996).

4. D. S. Darrow, et al., in Proceedings of the 26th EPS Conference on Controlled Fusion and Plasma Physics, Maastricht, The Netherlands, 14-18 June 1999.

5. D. S. Darrow, et al., Rev. Sci. Instrum. 72, 784 (2001). 


\section{External Distribution}

Plasma Research Laboratory, Australian National University, Australia

Professor I.R. J ones, Flinders University, Australia

Professor J oão Canalle, Instituto de Fisica DEQ/IF - UERJ , Brazil

Mr. Gerson O. Ludwig, Instituto Nacional de Pesquisas, Brazil

Dr. P.H. Sakanaka, Instituto Fisica, Brazil

The Librarian, Culham Laboratory, England

Library, R61, Rutherford Appleton Laboratory, England

Mrs. S.A. Hutchinson, JET Library, England

Professor M.N. Bussac, Ecole Polytechnique, France

Librarian, Max-Planck-Institut für Plasmaphysik, Germany

J olan Moldvai, Reports Library, MTA KFKI-ATKI, Hungary

Dr. P. Kaw, Institute for Plasma Research, India

Ms. P.J . Pathak, Librarian, Insitute for Plasma Research, India

Ms. Clelia De Palo, Associazione EURATOM-ENEA, I taly

Dr. G. Grosso, Instituto di Fisica del Plasma, Italy

Librarian, Naka Fusion Research Establishment, J AERI, J apan

Library, Plasma Physics Laboratory, Kyoto University, J apan

Research Information Center, National Institute for Fusion Science, J apan

Dr. O. Mitarai, Kyushu Tokai University, J apan

Library, Academia Sinica, Institute of Plasma Physics, People's Republic of China

Shih-Tung Tsai, Institute of Physics, Chinese Academy of Sciences, People's Republic of China

Dr. S. Mirnov, TRINITI, Troitsk, Russian Federation, Russia

Dr. V.S. Strelkov, Kurchatov Institute, Russian Federation, Russia

Professor Peter Lukac, Katedra Fyziky Plazmy MFF UK, Mlynska dolina F-2, Komenskeho Univerzita, SK-842 15 Bratislava, Slovakia

Dr. G.S. Lee, Korea Basic Science Institute, South Korea

Mr. Dennis Bruggink, Fusion Library, University of Wisconsin, USA

Institute for Plasma Research, University of Maryland, USA

Librarian, Fusion Energy Division, Oak Ridge National Laboratory, USA

Librarian, Institute of Fusion Studies, University of Texas, USA

Librarian, Magnetic Fusion Program, Lawrence Livermore National Laboratory, USA

Library, General Atomics, USA

Plasma Physics Group, Fusion Energy Research Program, University of California at San Diego, USA

Plasma Physics Library, Columbia University, USA

Alkesh Punjabi, Center for Fusion Research and Training, Hampton University, USA

Dr. W.M. Stacey, Fusion Research Center, Georgia Institute of Technology, USA

Dr. J ohn Willis, U.S. Department of Energy, Office of Fusion Energy Sciences, USA

Mr. Paul H. Wright, Indianapolis, Indiana, USA 
The Princeton Plasma Physics Laboratory is operated by Princeton University under contract with the U.S. Department of Energy.

\author{
Information Services \\ Princeton Plasma Physics Laboratory \\ P.O. Box 451 \\ Princeton, NJ 08543
}

Phone: 609-243-2750

Fax: 609-243-2751

e-mail: pppl_info@pppl.gov

Internet Address: http://www.pppl.gov 